\title{
Integrative analysis of transcription factors and microRNAs in ovarian cancer cell spheroids
}

\author{
Hyun Park', Sohyun Hwang ${ }^{2}$, Ju-Yeon Jeong ${ }^{2,3}$, Sang Geun Jung ${ }^{1}$, Min Chul Choi', Won Duk Joo', \\ Seung Hun Song ${ }^{1}$, Chan Lee ${ }^{1}$ and Hee Jung $\mathrm{An}^{2,3^{*}}$
}

\begin{abstract}
Background: Cancer stem cells (CSCs) can self-renew, proliferate into differentiated cells, or enter a quiescent state and are regarded to cause chemoresistance and recurrence. An integrative analysis of transcription factors (TF) and miRNAs was performed in ovarian CSC-enriched spheroid-forming cells (SFCs) to identify factors relevant to ovarian CSCS.

Methods: Fresh tumor cells from three ovarian cancer patients were cultured in standard and in selective medium. The mRNAs and miRNAs that exhibited significant differential expression between SFCs and adherent cells were identified using mRNA and miRNAs microarrays. Target genes of miRNAs were further selected if predicted with TargetScan by half of the miRNAs or more. Gene enrichment analysis was performed on over- or under-expressed mRNAs and target genes of miRNAs using DAVID tools. Complex regulatory networks were combined from TFgenes and miRNA-genes interactions using the MAGIA webtool.

Results: A total of 1245 mRNA and 55 miRNAs were differentially expressed ( $p$-value $<0.05$, paired t-test). Elevation of transcription-related processes and suppression of focal adhesion pathway were noted in SFCs, according to the enrichment analyses. Transcriptional hyperactivity is a known characteristic of the stem cell transcriptome. The integrative network suggested that cell cycle was arrested in SFCs where over-expressed EGR1 and under-expressed MYC and miR-130a-3p had multiple connections with target genes.

Conclusions: MYC, EGR1, and miR-130a-3p were hubs in our integrative analysis of ovarian CSC-enriched SFCs, suggesting that ovarian cancer SFCs display a stem cell identity with the quiescent phenotype where adhesionand cell cycle-related genes were suppressed.
\end{abstract}

Keywords: Ovarian epithelial carcinoma, Spheroid-forming cells, Cancer stem cells, Transcription factors, microRNAs

\section{Background}

Ovarian cancer is a devastating gynecologic malignancy. Most patients are diagnosed at an advanced stage, and are vulnerable to recurrence of the disease. About 70\% of cases have intraperitoneal dissemination at initial diagnosis [1]. These cases usually regress completely following primary cytoreductive surgery and adjuvant

\footnotetext{
* Correspondence: hjahn@cha.ac.kr

2Department of Pathology, College of Medicine, CHA University, Seongnam,

351 Yatap-dong, Bundang-gu, Seongnam-si, Gyeonggi-do 13496, South Korea

${ }^{3}$ Institute of Clinical Research, College of Medicine, CHA University, Seongnam, Gyeonggi-do, South Korea

Full list of author information is available at the end of the article
}

chemotherapy targeting residual disease. However, most patients experience recurrence, which suggests the presence of chemoresistant microlesions.

Cancer cell aggregates or spheroids are an important step in metastasis and cell survival in chemotherapy [2]. After ovarian cancer cells are shed from the primary tumor, they grow as spheres floating in ascites and disseminate through the peritoneal cavity [3]. Spheroids are proposed to mainly consist of cancer stem cells (CSCs) which have potential to evade therapy [4]. Additionally spheroids in this non-adherent condition enter a quiescent or dormant state, a temporary arrest of proliferation, and become refractory to chemotherapy [5].

(c) The Author(s). 2020 Open Access This article is distributed under the terms of the Creative Commons Attribution 4.0 International License (http://creativecommons.org/licenses/by/4.0/), which permits unrestricted use, distribution, and reproduction in any medium, provided you give appropriate credit to the original author(s) and the source, provide a link to the Creative Commons license, and indicate if changes were made. The Creative Commons Public Domain Dedication waiver (http://creativecommons.org/publicdomain/zero/1.0/) applies to the data made available in this article, unless otherwise stated. 
Cellular quiescence is genetically controlled by a combination of environmental cues from stem cell niche and cell intrinsic factors especially associated with cell cycle and transcriptional regulation [6, 7]. MiRNAs are wellknown regulators in numerous biologic processes including proliferation and metastasis. Some miRNAs are reported to govern the phenotypes of tumors such as outgrowth or prolonged dormancy [8].

In this study we examined and integrated the mRNA expression of transcription factors and miRNA expressions of spheroids derived from primary ovarian cancers to identify factors regulating ovarian cancer stem cells. The key regulators and their functions were reviewed in terms of stem cell features, which may present relevant targets for novel therapeutics to reduce treatment resistance and recurrence of ovarian cancer.

\section{Materials and methods}

\section{Patients and tissue samples}

Tissues were sampled from specimens obtained from staging operation including oophorectomy for high grade serous adenocarcinoma of ovary. A total of five patients were initially enrolled, however three corresponding sets from 3 patients were studied for matched analysis of mRNA and miRNA expression because one patient was proved to be low grade serous carcinoma, and one sample did not pass the RNA QC for microarray. The clinicopathological characteristics of the cases were listed on Additional file 1: Table S1. Informed consent was obtained from the patients before surgery. This study was approved by the Ethical Committee of CHA Bundang Medical Center (CHAMC 2009-019).

\section{Primary cell culture and spheroid-forming cell (SFC) isolation}

Tumors were mechanically dissected into small pieces and enzymatically digested at $37^{\circ} \mathrm{C}$ for $1 \mathrm{~h}$ into singlecell suspensions using collagenase A $(50 \mathrm{U} / \mathrm{mL}$, Roche, Basel, Switzerland) contained in $\mathrm{Ca} / \mathrm{Mg}$-free phosphatebuffered saline. Cells were incubated with Ber-EP4coated magnetic Dynabeads (Life Technologies, Grand Island, NY) for $30 \mathrm{~min}$ to select epithelial cells, which were then cultured in RPMI medium (Gibco/Life Technologies, Grand Island, NY) containing 10\% fetal bovine serum, $1 \%$ penicillin-streptomycin, and $20 \mathrm{ng} / \mathrm{mL}$ epidermal growth factor (Life Technologies).

For spheroid formation, single cells were plated on ultra-attachment six-well culture plates (Corning, Acton, MA) at a density of $1 \times 10^{\wedge} 3$ cells $/ \mathrm{cm}^{2}$ in serum-free Dulbecco's modified Eagle's medium/F12 medium (Life Technologies) supplemented with $20 \mathrm{ng} / \mathrm{mL}$ epidermal growth factor (Life Technologies), $10 \mathrm{ng} / \mathrm{mL}$ basic fibroblast growth factor (Sigma-Aldrich), and $5 \mu \mathrm{g} / \mathrm{mL}$ insulin
(Sigma-Aldrich). Spheroid formation of 50-100 cells was assessed at 7 days after seeding.

\section{RNA extraction}

Cultured SFCs were passed through a tube installed with nylon mesh of $35 \mu \mathrm{m}$ pore-size. Only the globular SFCs on the mesh were collected and pelleted to remove the media. RNA was isolated from SFCs and corresponding primary cancer cells at the same passage (passage2) using TRIzol reagent (Life Technologies), according to the manufacturer's instructions. Total RNA quantification was performed using a Nanodrop spectrophotometer (NanoDrop Technologies, Inc., Wilmington, DE, USA). The integrity of the isolated RNA and miRNA was examined by OD 260/280, OC260/230, 28S/18S ratio and RNA integration number (RIN) using Agilent 2100 Bioanalyzer. The RNA quality was listed up in Additional file 1: Table S2. All 3 matched samples, which passed the RNA QC, were referred to microarray analysis.

\section{cDNA microarray analysis}

Synthesis of target cRNA probes and hybridization were performed using Agilent's Low RNA Input Linear Amplification kit (Agilent Technology, USA). Briefly $25 \mathrm{ng}$ total RNA was reversely transcribed to dsDNA with cDNA master mix. Then, dsDNA were labelled with $\mathrm{Cy}$ anine 3-pCp (Cy3) or Cyanine 3-pCp (Cy5) and transcribed to cRNA according to manufacturer's protocol. Amplified and labeled cRNA was purified on the cRNA Cleanup Module (Agilent Technology). Each $850 \mathrm{ng}$ of Cy3-labeled and Cy5-labeled cRNA target were mixed and fragmented for hybridization. The fragmented cRNA was pipetted directly onto assembled Human Oligo Microarray (60 K) (Agilent Technology).

Hybridized images were scanned using a DNA microarray scanner and quantified with Feature Extraction Software (Agilent Technology). Data normalization and selection of significantly changed genes was performed using GeneSpring GX 7.3 (Agilent Technology). Intensity-dependent normalization (LOWESS) was performed, where the ratio was reduced to the residual of the Lowess fit of the intensity vs. ratio curve. The averages of normalized ratios were calculated by dividing the average normalized signal channel intensity by the average normalized control channel intensity.

\section{microRNA microarray}

MicroRNA microarray analysis was performed as instructed by the manufacturer. One hundred nanograms of RNA from each sample was labeled with Cy3 using Agilent's miRNA Complete Labeling and Hyb Kit. The Cy3-labeled RNAs were hybridized to the miRNA microarray (Agilent Human miRNA 8*60 K, Rel 18.0). 
The miRNA microarray was then scanned using the Agilent G2600D microarray scanner. Raw data for the same gene in primary ovarian cancer cells and SFCs were summarized in the Agilent Feature Extraction software package (v11.0.1.1), which generated the gene view file and provided expression data for each gene probed on the array. Array data were filtered using gIsGeneDetected $=1$ for all samples (1: detected). Logarithmically transformed miRNA gtotalGeneSignal values were normalized with the quantile method [9]. R statistical language software package (v. 2.15.0) performed the normalize.quantiles function of the preprocessCore package (https://www.rdocumentation.org/packages/preprocessCore/versions/1.34.0/topics/normalize.quantiles). The comparative analysis of results from primary cancer cells and SFCs was based on fold changes.

\section{Gene enrichment analysis}

mRNAs and miRNAs that had been differently expressed between spheroid and parental cells with significance ( $p$ value $<0.05$, paired $t$-test) based on microarray data were included in the analysis. Target genes of miRNAs were identified with TargetScan (http://www.targetscan.org) and further selected if they were predicted by at least half of the miRNAs. The gene list was submitted to the Database for Annotation, Visualization, and Integrated Discovery (DAVID), version 6.7 (http://david.abcc. ncifcrf.gov/) and annotated by Gene Ontology enrichment analysis and Kyoto Encyclopedia of Genes and Genomes (KEGG) pathway enrichment analysis (https:// www.genome.jp/kegg/). The pathway enrichment was regarded to be significant when the $p$-value of modified Fisher's exact test was less than 0.05 . .

\section{Integrative network analysis}

The data flow for integrative analysis is summarized in Fig. 1. The probe lists of genes and miRNA with statistical significance ( $\mathrm{p}$-value $<0.05$, paired $\mathrm{t}$-test) were processed and uploaded to each matrix. All differentially expressed probes were included in the selection criteria in order to identify the effects of under-expressed regulators. The integrative analysis was conducted with

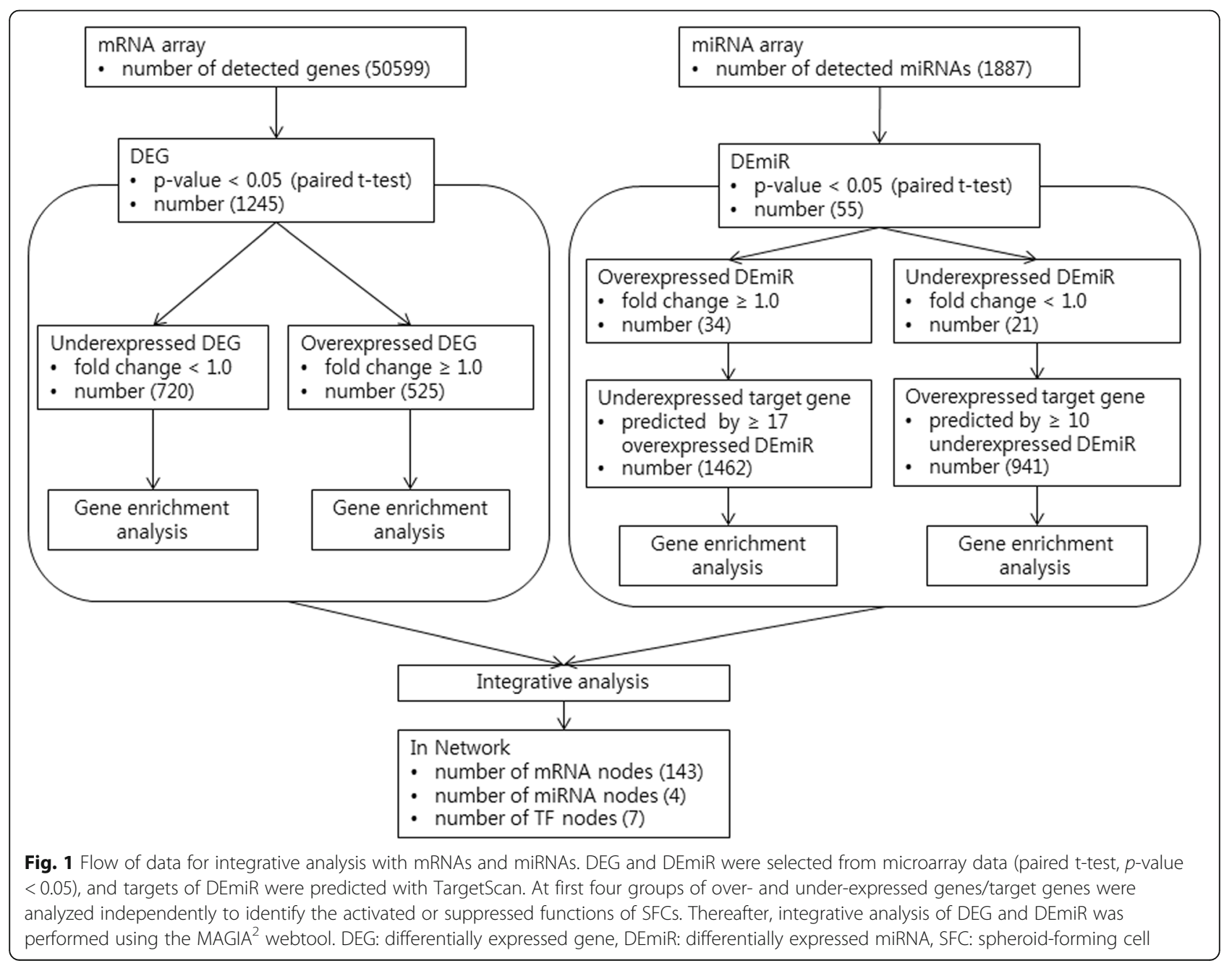


Table 1 Gene ontology annotated from over-expressed genes in spheroid cells compared with parental cells

\begin{tabular}{|c|c|c|c|c|}
\hline Term & Count & $\%$ & $P$-Value & Bonferron \\
\hline GO:0006351 transcription, DNA-templated & 96 & 18.3 & $2.99 \mathrm{E}-11$ & $5.28 \mathrm{E}-08$ \\
\hline $\begin{array}{l}\text { GO:0006355 regulation of transcription, } \\
\text { DNA-templated }\end{array}$ & 73 & 13.9 & $2.40 \mathrm{E}-08$ & 4.23E-05 \\
\hline $\begin{array}{l}\text { GO:0000122 negative regulation of transcription } \\
\text { from RNA polymerase II promoter }\end{array}$ & 34 & 6.4 & 4.40E-04 & 0.540151 \\
\hline $\begin{array}{l}\text { GO:0045893 positive regulation of transcription, } \\
\text { DNA-templated }\end{array}$ & 26 & 4.9 & $9.82 \mathrm{E}-04$ & 0.82318 \\
\hline $\begin{array}{l}\text { GO:0006366 transcription from RNA polymerase } \\
\text { II promoter }\end{array}$ & 25 & 4.7 & 0.001996 & 0.970526 \\
\hline GO:0010467 gene expression & 6 & 1.1 & 0.006248 & 0.999984 \\
\hline GO:0051726 regulation of cell cycle & 9 & 1.7 & 0.011435 & 1 \\
\hline GO:0036498 IRE1-mediated unfolded protein response & 6 & 1.1 & 0.014689 & 1 \\
\hline GO:0051569 regulation of histone H3-K4 methylation & 3 & 0.5 & 0.019287 & 1 \\
\hline GO:0033762 response to glucagon & 3 & 0.5 & 0.023722 & 1 \\
\hline
\end{tabular}

MAGIA2 (http://gencomp.bio.unipd.it/magia2), which is a web application incorporating in silico target prediction, miRNA, and gene expression data [10]. The whole results were downloaded as tab delimited files which describe TF-target and miRNA-target data. Cytoscape was used to import and merge the files in order to revisualize the network [11]. The activity of biologic processes of interest was evaluated with chi-square test which analyzes the relationship between the expression level of genes (low vs. high group) and a particular process to which the genes belong (one process vs. others group).

\section{Results}

\section{Characteristics of isolated primary carcinoma cells and} spheroid-forming cells

After tumor cells isolation, the immune cells comprised about $10-15 \%$ of the whole isolated cells. After selection with Ber-EP4-coated magnetic dynabeads, the immune cells were less than 1\% (FACS data, Additional file 1: Figure S1). Therefore, the cultured cells were said to be purely carcinoma cells.

The nonadherent spherical clusters of 50-100 cells were observed 1 week after plating on spheroid-forming assay. The efficiency of spheroid formation from the inoculated cells was $2.4 \% \pm 0.2 \%$ in the first generation. The spheroid-forming capacity in the second generation was similar to the first $(2.3 \% \pm 0.3 \%)$ [12].

\section{Differential expression of mRNA and miRNA}

In SFCs compared with parental cancer cells, 1245 genes were differentially expressed $(p<0.05)$, with 720 (57.8\%) under-expressed and 525 (42.2\%) over-expressed. For miRNAs, 55 were selected which were differentially expressed $(p<0.05)$ where $21(38.1 \%)$ were underexpressed and 34 (61.9\%) were over-expressed in SFCs.

Table 2 KEGG pathways annotated from over-expressed genes in spheroid cells compared with parental cells

\begin{tabular}{|c|c|c|c|c|}
\hline Term & Count & $\%$ & $P$-Value & Benjamini \\
\hline hsa00190:Oxidative phosphorylation & 9 & 1.7 & 0.006861 & 0.731536 \\
\hline hsa05016:Huntington's disease & 11 & 2.0 & 0.007159 & 0.496491 \\
\hline hsa05010:Alzheimer's disease & 10 & 1.9 & 0.008861 & 0.432572 \\
\hline hsa04260:Cardiac muscle contraction & 6 & 1.1 & 0.020595 & 0.629784 \\
\hline hsa05012:Parkinson's disease & 8 & 1.5 & 0.030054 & 0.688289 \\
\hline $\begin{array}{l}\text { hsa04932:Non-alcoholic fatty liver } \\
\text { disease (NAFLD) }\end{array}$ & 8 & 1.5 & 0.039968 & 0.727043 \\
\hline hsa04720:Long-term potentiation & 5 & 0.9 & 0.049961 & 0.753023 \\
\hline $\begin{array}{l}\text { hsa04141:Protein processing in } \\
\text { endoplasmic reticulum }\end{array}$ & 8 & 1.5 & 0.065682 & 0.8025 \\
\hline hsa04931:Insulin resistance & 6 & 1.1 & 0.077341 & 0.818825 \\
\hline hsa01212:Fatty acid metabolism & 4 & 0.7 & 0.079851 & 0.795971 \\
\hline
\end{tabular}


Table 3 Gene ontology annotated from under-expressed genes in spheroid cells compared with parental cells

\begin{tabular}{|c|c|c|c|c|}
\hline Term & Count & $\%$ & $P$-Value & Benjamini \\
\hline GO:0006936 muscle contraction & 17 & 2.3 & $9.22 \mathrm{E}-07$ & 0.002228 \\
\hline $\begin{array}{l}\text { GO:0060314 regulation of ryanodine- } \\
\text { sensitive calcium-release channel activity }\end{array}$ & 7 & 0.9 & 3.27E-05 & 0.038794 \\
\hline GO:0098609 cell-cell adhesion & 23 & 3.2 & 2.24E-04 & 0.165232 \\
\hline $\begin{array}{l}\text { GO:0010881 regulation of cardiac muscle } \\
\text { contraction by regulation of the release } \\
\text { of sequestered calcium ion }\end{array}$ & 6 & 0.8 & 3.97E-04 & 0.213532 \\
\hline $\begin{array}{l}\text { GO:0044319 wound healing, spreading } \\
\text { of cells }\end{array}$ & 5 & 0.7 & $5.85 \mathrm{E}-04$ & 0.246555 \\
\hline $\begin{array}{l}\text { GO:0006636 unsaturated fatty acid } \\
\text { biosynthetic process }\end{array}$ & 5 & 0.7 & 0.001483 & 0.450441 \\
\hline $\begin{array}{l}\text { GO:0072661 protein targeting to } \\
\text { plasma membrane }\end{array}$ & 6 & 0.8 & 0.001834 & 0.46994 \\
\hline $\begin{array}{l}\text { GO:1901380 negative regulation of } \\
\text { potassium ion transmembrane transport }\end{array}$ & 4 & 0.5 & 0.002087 & 0.468405 \\
\hline GO:0070527 platelet aggregation & 7 & 0.9 & 0.002822 & 0.532242 \\
\hline $\begin{array}{l}\text { GO:0010880 regulation of release of } \\
\text { sequestered calcium ion into cytosol } \\
\text { by sarcoplasmic reticulum }\end{array}$ & 5 & 0.7 & 0.003059 & 0.523566 \\
\hline
\end{tabular}

A total of 921 and 1420 target genes were listed that had been predicted multiple times by more than 10 underexpressed miRNAs and 17 or more over-expressed miRNAs, respectively. The data of mRNA and miRNA microarray can be accessed through Gene Expression Omnibus (GEO) Series accession number GSE136924 and GSE136925 respectively (www.ncbi.nlm.nih.gov/ geo).

The functions of those genes were analyzed using DAVID for gene enrichment analyses (Tables 1, 2, 3, 4, 5, 6, 7 and 8). Transcription, DNA-templated was the most significantly altered biologic process in both overexpressed mRNAs (false discovery rate, FDR $=5.3 \mathrm{E}-8$ ) and target genes of under-expressed miRNAs (FDR = 3.9E-3). According to KEGG pathway analysis, focal adhesion (FDR $=2.3 \mathrm{E}-4)$ and ErbB pathways (FDR = 6.2E-3) were affected the most in under-expressed mRNAs and target genes of over-expressed miRNAs, respectively, which were suppressed in SFCs.

\section{Network analysis}

We found a total of 147 nodes and 151 interactions with FDR $<0.05$ (Fig. 2). There were seven TFs and four miRNAs as regulators. While three TFs had only one interaction of TF-miRNA or miRNA-TF, four had multiple interactions with target genes of various functions, such as transcription, cell adhesion, apoptosis, proliferation, and cell cycle. There were four miRNAs where miR$130 \mathrm{a}-3 \mathrm{p}$ had multiple interactions with genes of transcription, apoptosis, and proliferation. Three regulators,

Table 4 KEGG pathways annotated from under-expressed genes in spheroid cells compared with parental cells

\begin{tabular}{|c|c|c|c|c|}
\hline Term & Count & $\%$ & $P$-Value & Benjamini \\
\hline hsa04510:Focal adhesion & 25 & 3.5 & $9.56 \mathrm{E}-07$ & $2.44 \mathrm{E}-04$ \\
\hline hsa04810:Regulation of actin cytoskeleton & 23 & 3.2 & $1.58 \mathrm{E}-05$ & 0.002008 \\
\hline hsa04270:Vascular smooth muscle contraction & 16 & 2.2 & 3.63E-05 & 0.003084 \\
\hline hsa05205:Proteoglycans in cancer & 21 & 2.9 & 7.53E-05 & 0.004789 \\
\hline hsa04921:Oxytocin signaling pathway & 17 & 2.3 & 1.89E-04 & 0.009584 \\
\hline hsa04520:Adherens junction & 11 & 1.5 & $3.41 \mathrm{E}-04$ & 0.014382 \\
\hline hsa04310:Wnt signaling pathway & 14 & 1.9 & 0.002365 & 0.082638 \\
\hline hsa01100:Metabolic pathways & 64 & 8.9 & 0.00614 & 0.178252 \\
\hline hsa00230:Purine metabolism & 15 & 2.1 & 0.00754 & 0.193017 \\
\hline hsa04912:GnRH signaling pathway & 10 & 1.4 & 0.007892 & 0.182938 \\
\hline
\end{tabular}


Table 5 Gene ontology annotated from genes targeted by under-expressed miRNAs in spheroid cells compared with parental cells

\begin{tabular}{|c|c|c|c|c|}
\hline Term & Count & $\%$ & $P$-Value & Benjamini \\
\hline GO:0006351 transcription, DNA-templated & 141 & 15.3 & $1.34 \mathrm{E}-06$ & 0.00394 \\
\hline $\begin{array}{l}\text { GO:0006355 regulation of transcription, } \\
\text { DNA-templated }\end{array}$ & 105 & 11.4 & 1.47E-04 & 0.19426 \\
\hline GO:0007611 learning or memory & 9 & 0.9 & 2.75E-04 & 0.235702 \\
\hline GO:0060509 Type I pneumocyte differentiation & 4 & 0.4 & 0.00107 & 0.544146 \\
\hline $\begin{array}{l}\text { GO:0045944 positive regulation of transcription } \\
\text { from RNA polymerase II promoter }\end{array}$ & 70 & 7.6 & 0.001317 & 0.538713 \\
\hline GO:0001782 B cell homeostasis & 6 & 0.6 & 0.001365 & 0.487511 \\
\hline $\begin{array}{l}\text { GO:0000122 negative regulation of transcription } \\
\text { from RNA polymerase II promoter }\end{array}$ & 54 & 5.8 & 0.00178 & 0.526265 \\
\hline GO:0017148 negative regulation of translation & 10 & 1.0 & 0.00184 & 0.491213 \\
\hline GO:0016055 Wnt signaling pathway & 20 & 2.1 & 0.001982 & 0.476491 \\
\hline GO:0035278 miRNA mediated inhibition of translation & 5 & 0.5 & 0.002021 & 0.447845 \\
\hline
\end{tabular}

EGR1 ( $\mathrm{fc}=2.479)$, MYC ( $\mathrm{fc}=0.387$ ), and $\mathrm{miR}-130 \mathrm{a}-3 \mathrm{p}$ $(\mathrm{fc}=0.381)$, were more differentially expressed $(\geq 2$ or $\leq$ 0.5 -fold change $(\mathrm{fc}))$ than others $(2<\mathrm{fc}<0.5)$ (Table 9).

Transcription-related genes were the most common in the network that combined upregulated and downregulated target genes. The genes involved in cell adhesion (chi-square test, $p=0.019)$ and cell cycle $(p=0.043)$ were significantly downregulated in SFCs, implying these biologic processes are inactive in these cells. All components of cell adhesion (PDLIM5, $\mathrm{fc}=0.201 ;$ CALD1, $\mathrm{fc}=$ 0.281; DIAPH3, fc $=0.194 ;$ MACF1, fc $=0.741 ;$ PPME1, $\mathrm{fc}=0.548 ; \quad$ TMEM $47, \quad \mathrm{fc}=0.330 ; \quad$ TLN $1, \quad \mathrm{fc}=0.410 ;$ PPME1, fc $=0.548)$ and cycle (CCND1, fc $=0.493$; MAPK3, fc $=0.521 ; \mathrm{PIN} 1, \mathrm{fc}=0.656 ;$ CUL4B, $\mathrm{fc}=0.425$; CRIM1, $\mathrm{fc}=0.043$; THRA, $\mathrm{fc}=0.676$ ) were downregulated, most of which were connected with underexpressed MYC. Chromatin remodelers (CHD4, $\mathrm{fc}=$ 1.656; $\mathrm{BAZ2B}, \mathrm{fc}=1.800$; and SMARCB1, $\mathrm{fc}=1.272)$ associated with transcriptional hyperactivity were elevated in the network.
CSC marker and factors associated with stem cell maintenance, such as NOTCH1 ( $\mathrm{fc}=1.718), \mathrm{BCL} 9$ ( $\mathrm{fc}=$ 1.676), and SOX4 ( $\mathrm{fc}=1.683)$ were overexpressed. Stem cell intrinsic factors that control the reversible arrest of cell cycle were noted in this network. Over-expressed EGR1 and CHD4 and under-expressed MYC and CCND1 corresponded to the quiescent state of stem cells.

\section{Discussion}

CSCs are thought to be the origin of recurrence and have the potential to survive chemotherapy. One feature of stem cells, cellular dormancy or quiescence, has increasingly gained interest as a relevant step in metastasis and chemoresistance.

Suspension culture systems used in this study stimulate symmetrical division and expand the stem cell compartment. In ovarian cancer, spheroids were first cultured from cancer cells obtained from peritoneal ascites in 2005 by Bapat et al. [13]. Subsequent studies reported that

Table 6 KEGG pathways annotated from genes targeted by under-expressed miRNAs in spheroid cells compared with parental cells

\begin{tabular}{lllll}
\hline Term & Count & $\%$ & $P$-Value & Benjamini \\
\hline hsa05223:Non-small cell lung cancer & 10 & 1.0 & 5.70 E-04 & 0.129304 \\
hsa04070:Phosphatidylinositol signaling system & 13 & 1.4 & $9.47 \mathrm{E}-04$ & 0.001238 \\
hsa05231:Choline metabolism in cancer & 13 & 1.4 & 0.001713 & 0.09708 \\
hsa05214:Glioma & 10 & 1.0 & 0.001786 \\
hsa04710:Circadian rhythm & 7 & 0.7 & 0.002413 & 0.098896 \\
hsa04713:Circadian entrainment & 12 & 1.3 & 0.005361 & 0.083219 \\
hsa05202:Transcriptional misregulation in cancer & 16 & 1.7 & 0.007051 & 0.093214 \\
hsa04550:Signaling pathways regulating & 14 & 1.5 & 0.008364 & 0.17023 \\
pluripotency of stem cells & & 0.9 & 0.011687 \\
hsa04664:Fc epsilon Rl signaling pathway & 9 & 0.9 & 0.202908 \\
hsa05220:Chronic myeloid leukemia & 9 & & 0.248486 \\
\hline
\end{tabular}


Table 7 Gene ontology annotated from genes targeted by over-expressed miRNAs in spheroid cells compared with parental cells

\begin{tabular}{|c|c|c|c|c|}
\hline Term & Count & $\%$ & $P$-Value & Benjamini \\
\hline $\begin{array}{l}\text { GO:0007156 homophilic cell adhesion via } \\
\text { plasma membrane adhesion molecules }\end{array}$ & 29 & 2.0 & $1.54 \mathrm{E}-05$ & 0.056544 \\
\hline GO:0046777 protein autophosphorylation & 30 & 2.1 & $2.90 \mathrm{E}-05$ & 0.053211 \\
\hline $\begin{array}{l}\text { GO:0086012 membrane depolarization during } \\
\text { cardiac muscle cell action potential }\end{array}$ & 7 & 0.4 & 1.87E-04 & 0.209386 \\
\hline GO:0006351 transcription, DNA-templated & 186 & 13.0 & $3.32 \mathrm{E}-04$ & 0.269164 \\
\hline $\begin{array}{l}\text { GO:0045893 positive regulation of transcription, } \\
\text { DNA-templated }\end{array}$ & 59 & 4.1 & 0.001122 & 0.571204 \\
\hline GO:0007417 central nervous system development & 20 & 1.4 & 0.00143 & 0.593301 \\
\hline GO:0061337 cardiac conduction & 11 & 0.7 & 0.001496 & 0.553802 \\
\hline GO:0051899 membrane depolarization & 8 & 0.5 & 0.001859 & 0.584091 \\
\hline GO:0018105 peptidyl-serine phosphorylation & 20 & 1.4 & 0.002322 & 0.6226 \\
\hline GO:0006810 transport & 42 & 2.9 & 0.002517 & 0.613515 \\
\hline
\end{tabular}

spheroids can be established from primary ovarian cancer tissues using this system [23]. The cancer cells which survived non-adherent substrates grew as spheroid cell clusters and presented features of CSC-like expression of CSC marker and tumorigenicity [24]. In our previous report, we also demonstrated that spheroids are enriched with cancer stem cells by showing the elevation of many stem cell markers, ALDH1, CD133, CD24, and SOX2 [12] that is in line with our current study.

In a suspension culture system for tumor cell spheroids, loss of adhesion and nutrient deprivation can promote growth arrest and cause CSCs to enter quiescence [2]. Our results are consistent with previous studies that suggested cell adhesion and cell cycle pathways were suppressed in quiescent or dormant tumor cells [4, 25].

Stem cells are transcriptionally active and express global regions of the whole genome rather than specific lineage genes [26]. This transcriptional hyperactivity is accompanied by chromatin-remodeling factors and general TFs [14]. Recently, quiescence has come to be regarded as actively regulated by TFs and epigenetic factors rather than dormant as a default [7]. In our study, both mRNA and miRNA analyses suggested that transcription-related functions were significantly hyperactivated relative to other specific functions (Tables 1,2 , 3, 4, 5, 6, 7 and 8). Chromatin remodelers (CHD4, BAZ2B, and SMARCB1) were also elevated in the network (Fig. 2). Considering the previous literature regarding spheroid culture in addition to the gene expression patterns of this study, our SFCs appeared to have more stem cell identity relative to parental cells from primary ovarian cancer.

In this study, EGR1 was the most over-expressed TF based on comprehensive analysis. Quiescent cells can exit or re-enter the cell cycle in response to environmental and cell intrinsic signs. EGR1 is an immediate response gene involved in cellular responses to stress and growth factors, and has been reported as an intrinsic regulator that promotes quiescence [6]. This can reduce tumor growth, but also leads to increased survival in response to stress signals in solid tumors. Mice with EGR1-KO presented an accelerated tumorigenesis in a two-step skin carcinogenesis study [15]. Meanwhile the phosphorylated form serves a protective function by inhibiting apoptosis of cells irradiated with UV [27].

The function of EGR1 is mediated with p53, a downstream tumor suppressor [15]. p53 is important in pathophysiology of ovarian cancer and high-grade serous ovarian cancers are ubiquitously TP53 mutant [28]. A p53 deficiency can promote cell cycle reentry through cell cycle-independent mechanisms $[16,29]$. The role of EGR1 in chemoresistance was presented recently. In a study investigating properties of CSC, gene expression was compared between CSCs and cisplatin-resistant cells

Table 8 KEGG pathways annotated from genes targeted by over-expressed miRNAs in spheroid cells compared with parental cells

\begin{tabular}{lllll}
\hline Term & Count & $\%$ & P-Value & Benjamini \\
\hline hsa04012:ErbB signaling pathway & 19 & 1.3 & $2.22 \mathrm{E}-05$ & 0.005825 \\
hsa04713:Circadian entrainment & 19 & 1.3 & $7.62 \mathrm{E}-05$ & 0.009974 \\
hsa04144:Endocytosis & 32 & 2.2 & $5.76 \mathrm{E}-04$ & 0.049252 \\
hsa04921:Oxytocin signaling pathway & 23 & 1.6 & $6.27 \mathrm{E}-04$ & 0.040372 \\
hsa05223:Non-small cell lung cancer & 12 & 0.8 & 0.001382 & 0.070185 \\
hsa04725:Cholinergic synapse & 18 & 1.2 & 0.001567 & 0.066448 \\
hsa04720:Long-term potentiation & 13 & 0.9 & 0.00172 & 0.062632 \\
hsa04150:mTOR signaling pathway & 12 & 0.8 & 0.001864 & 0.059484 \\
hsa04068:FoxO signaling pathway & 20 & 1.4 & 0.002159 & 0.061212 \\
hsa04020:Calcium signaling pathway & 24 & 1.6 & 0.002917 & 0.073956 \\
\hline
\end{tabular}




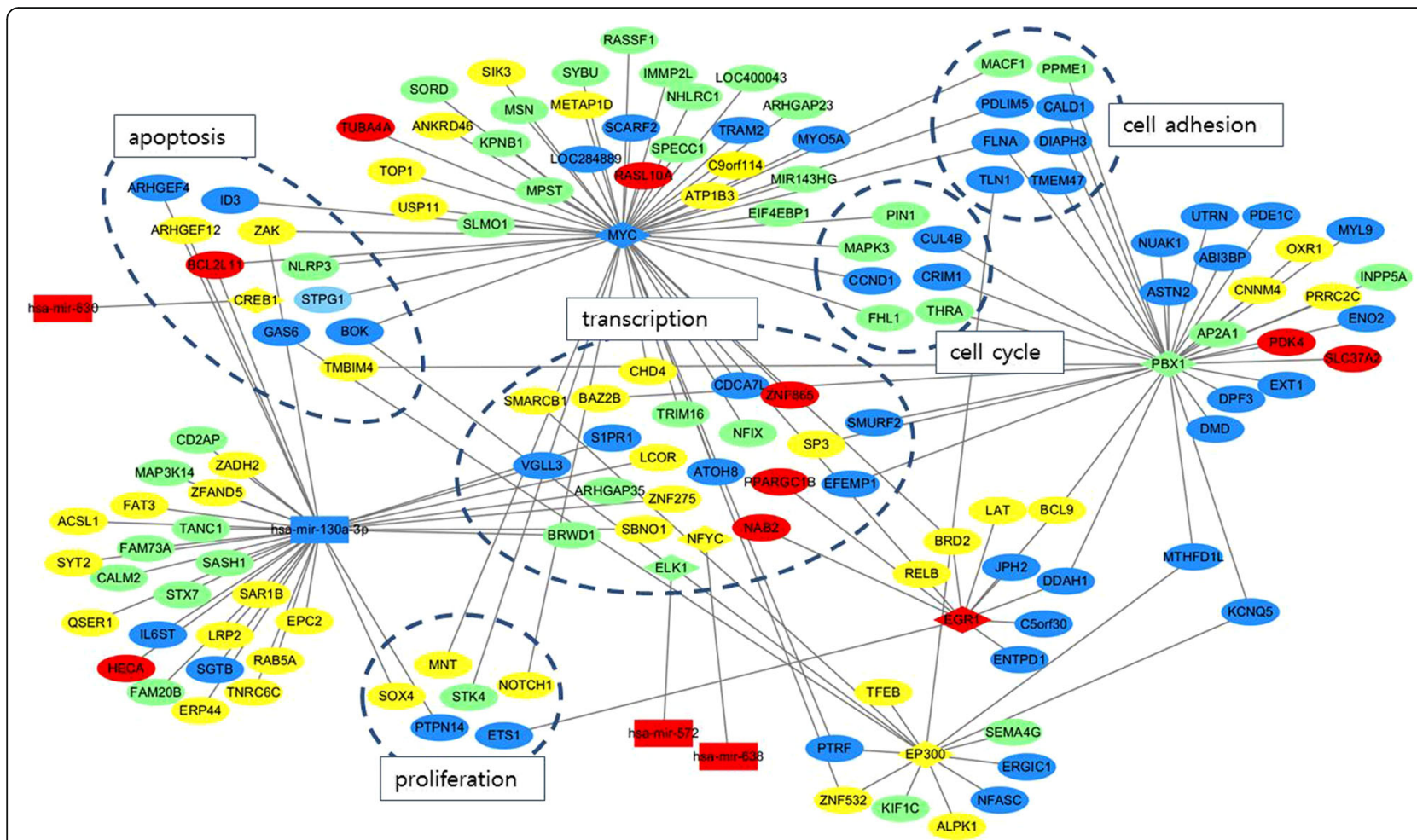

Fig. 2 Integrative network composed of TFs, miRNAs, and target genes. Genes of known function were grouped using dotted lines. Transcriptionrelated genes were most common, while genes of cell cycle and cell adhesion were suppressed in SFCs. EGR1, MYC, and miR-130a-3p were the main regulators to remain as a quiescent phenotype of stem cell. Rectangle: TF, ellipse: gene, diamond: miRNA, colors indicate fold change of the expression in spheroid-forming cells relative to parental cells (red: $\geq 2$, yellow: $2>$ to $>1$, green: $1>$ to $\geq 0.5$, blue: $>0.5$ ), SFC: spheroid-forming cell, TF: transcription factor

selected from lung cancer cells H460 [20]. There were close similarities between them, and EGR1 was one of the most significantly over-expressed genes in both cells. EGR1 enhances drug resistance by modulating MDR1 expression, according to a functional study [21].

The expression level of MYC, a master regulator, plays an important role in controlling the balance between proliferation and biosynthetic quiescence in stem cells [17]. There is a strict requirement for MYC activity to avoid cell death, and MYC inhibition induces stem cells to enter a quiescent state in various stem cell studies [18]. In hepatocellular carcinoma, MYC inactivation leads tumor cells to differentiate and many of them to die, but some cells showed stem cell properties and regained their proliferative capacity upon MYC reactivation [19]. In a mouse model, inactivation of MYC resulted in regression of liver tumors, and the tumor dormancy lasted for over 8 months.

MYC is necessary for quiescent cells to be activated rapidly from a poised state wherein multiple genes have

Table 9 Regulators with multiple connections in network and their roles in stem cells

\begin{tabular}{|c|c|c|c|c|c|}
\hline Regulators & Fold change & P-value & Function in tumor & Function in stem cell & Reference \\
\hline$\overline{\text { EGR1 }}$ & 2.479 & 0.045 & $\begin{array}{l}\text { Tumor suppressor, } \\
\text { Chemoresistance enhancer }\end{array}$ & Promote quiescence & [12], [13], [14] \\
\hline MYC & 0.387 & 0.036 & Proto-oncogene & $\begin{array}{l}\text { Inactivation induce } \\
\text { quiescence or differentiation }\end{array}$ & {$[15,16]$} \\
\hline PBX1 & 0.759 & 0.032 & $\begin{array}{l}\text { Stem cell reprogramming } \\
\text { factor, Chemoresistance } \\
\text { enhancer }\end{array}$ & Maintain quiescence & {$[17,18]$} \\
\hline EP300 & 1.484 & 0.005 & $\begin{array}{l}\text { Tumor suppressor, } \\
\text { Chemoresistance modulator }\end{array}$ & Modulate stemness & [19] \\
\hline miR-130a-3p & 0.381 & 0.007 & $\begin{array}{l}\text { Tumor suppressor, } \\
\text { Chemoresistance modulator }\end{array}$ & $\begin{array}{l}\text { Target genes maintain } \\
\text { quiescence }\end{array}$ & [20-22] \\
\hline
\end{tabular}


initiated transcription but not elongated further. MYC controls transcriptional elongation mediated by RNA polymerase II, and its expression can lead to mRNA synthesis that promotes rapid proliferation [30]. The level of MYC is positively related to cell number, which was confirmed in spheroids from a glioma cell line [22]. Therefore, the reduced MYC expression in our ovarian SFCs may play a role in the maintenance of cellular quiescence suppressing proliferation.

Post-transcriptional regulation is emerging as a major contributor to quiescence biology. Under-expressed miR-130a-3p (previous ID: miR-130a) was a major alteration in our network, and had multiple connections to target genes, including over-expressed SOX4. In a previous study measuring mRNA stability of the quiescent transcriptome, targets of the miR-130 family were enriched in day seven contact-inhibited fibroblasts compared to proliferating cells [31]. The miR-130 family may have a potential role in promoting proliferation, or its target genes in maintaining a quiescent state in stem cells. miR-130a-3p is under-expressed in chemoresistant non-small cell lung cancer [32]. miR-130a-3p directly targets SOX4, which can upregulate ABCG2, a main contributing factor to multidrug resistance, and induce the reduction of cisplatin resistance.

In our network analysis, other regulators which are reported to be relevant in the molecular regulation of stem cells were also noted. PBX1, a stem cell reprogramming factor, has been observed to promote CSC-like phenotypes, including resistance to platinum in ovarian cancer cells [33]. Loss of PBX1 resulted in impaired selfrenewal and quiescence in hematopoietic systems [34]. EP300 regulates transcription via chromatin remodeling as a histone acetyltransferase. Loss of EP300 was presented in multiple solid tumors, and was associated with increased tumorigenicity, CSC-like properties, and chemoresistance [35]. The roles of these TFs in our study were inconclusive because the directions of expression were opposite to those of previous studies.

Based on our results, the ovarian SFCs with quiescent features seem to be regulated by over-expressed EGR1, and under-expressed MYC and miR-130a-3p. These molecular mechanisms of ovarian CSC and its quiescence may provide insights into the biology of recurrence and metastasis. The novel agents affecting the key regulators may eradicate the chemoresistant quiescent lesion or activate minimally invasive disease to be susceptible for conventional chemotherapy. Our study could provide information for further studies to validate potential therapeutics.

There were limitations in our study. First, the number of cases was too small for our results to be applicable in general. Second, heterogeneity of cells could not be completely excluded. If ovarian CSCs could be sorted by
FACS, surface markers might have been helpful in selecting CSCs with more precision. However, the usage is often limited due to low specificity of surface marker and low viability of sorted cells [36]. Third, because this study was designed to compare the gene expression of ovarian CSCs and parental cells, it is possible that the results were biased for stemness rather than common features of cancer such as proliferation and survival. Thus, the results should be interpreted with caution and validated with further functional and clinical studies. Forth, we performed and compared the gene expression profiles of cultured primary cells vs. spheroid-forming cells with same passage without data for initial epithelial tumor cells (passage 0). We could not completely exclude the possible alteration of gene expression of culture primary cells from the initial tumor cells.

\section{Conclusions}

Two TFs, MYC and EGR1, and miR-130a-3p are hubs in the regulatory network of ovarian CSCs, where adhesion- and cell cycle-related genes were suppressed. The characteristic pattern of molecular expression in this study suggested that the SFCs remained in a quiescent state of CSC. Considering the clinical significance of a quiescent tumor populated with CSCs, our results may provide target molecules for further study to treat the chemoresistance and recurrence of ovarian cancer.

\section{Supplementary information}

Supplementary information accompanies this paper at https://doi.org/10. 1186/s13048-020-00618-7.

Additional file 1 Table S1. The Patient information. Table S2. The RNA QC result of 3 primary cancer cells and their corresponding spheroid forming cells. Figure S1. The Facs analysis for immune cells in representative primary tumor cells before and after Ber-Ep4 Dynabead treatment.

\begin{abstract}
Abbreviations
CDNA: Complementary DNA; CSC: Cancer stem cell; EGR1: Early growth response protein 1; EP300: E1A binding protein P300; miRNA: MicroRNA; mRNA: Messenger RNA; MYC: BHLH transcription factor; PBX1: Pre-B-cell leukemia homeobox 1; SFC: Spheroid-forming cell; SOX4: SRY (sex determining region Y)-related HMG-box 4; TF: Transcription factor
\end{abstract}

\section{Acknowledgements}

Not applicable.

\section{Availability of data and material}

The datasets used and/or analysed during the current study are accessible through Gene Expression Omnibus (GEO) Series accession number GSE136924 and GSE136925 (www.ncbi.nlm.nih.gov/geo).

\section{Authors' contributions}

HP mainly interpreted the data, conducted integrative analysis and prepared the manuscript as a major contributor. SH and SGJ collected the microarray data and performed the statistical analysis. JJ, SHS and WDJ contributed to designing the study and then cultured the spheroid-forming cells and isolated the RNAs. CL and HJA designed the study and revised the manuscript. All authors read and approved the final manuscript 


\section{Funding}

This research was supported by a grant from the Korea Health Technology R\&D Project through the Korea Health Industry Development Institute funded by the Ministry of Health \& Welfare, Republic of Korea (grant number: HI16C1559) and by the National Research Foundation of Korea (NRF) grant funded by the Korea government (MSIT) (grant number:

2017R1D1A1B03035627)

\section{Ethics approval and consent to participate}

The study was approved by the ethics committee of CHA Bundang Medical Center (CHAMC 2009-019) and informed consent was obtained from each participants.

\section{Consent for publication}

Not applicable.

\section{Competing interests}

The authors declare that they have no competing interests.

\section{Author details}

'Division of Gynecologic Oncology, Department of Obstetrics and Gynecology, College of Medicine, CHA University, Seongnam, Gyeonggi-do, South Korea. ${ }^{2}$ Department of Pathology, College of Medicine, CHA University, Seongnam, 351 Yatap-dong, Bundang-gu, Seongnam-si, Gyeonggi-do 13496, South Korea. Institute of Clinical Research, College of Medicine, CHA University, Seongnam, Gyeonggi-do, South Korea.

Received: 26 June 2019 Accepted: 4 February 2020

\section{Published online: 11 February 2020}

\section{References}

1. Marsden DE, Friedlander M, Hacker NF. Current management of epithelial ovarian carcinoma: a review. Semin Surg Oncol. 2000;19:11-9.

2. Sosa MS, Bragado P, Aguirre-Ghiso JA. Mechanisms of disseminated cancer cell dormancy: an awakening field. Nat Rev Cancer. 2014;14:611-22.

3. Shepherd TG, Theriault BL, Campbell EJ, Nachtigal MW. Primary culture of ovarian surface epithelial cells and ascites-derived ovarian cancer cells from patients. Nat Protoc. 2006;1:2643-9.

4. Ishiguro T, Ohata H, Sato A, Yamawaki K, Enomoto T, Okamoto K. Tumorderived spheroids: relevance to cancer stem cells and clinical applications. Cancer Sci. 2017;108:283-9.

5. Almog N. Molecular mechanisms underlying tumor dormancy. Cancer Lett. 2010;294:139-46.

6. Yamada T, Park CS, Lacorazza HD. Genetic control of quiescence in hematopoietic stem cells. Cell Cycle. 2013;12:2376-83.

7. Cheung TH, Rando TA. Molecular regulation of stem cell quiescence. Nat Rev Mol Cell Biol. 2013;14:329-40.

8. Almog N, Ma L, Schwager C, Brinkmann BG, Beheshti A, Vajkoczy P, et al. Consensus micro RNAs governing the switch of dormant tumors to the fast-growing angiogenic phenotype. PLoS One. 2012;7:e44001.

9. Bolstad BM, Irizarry RA, Astrand M, Speed TP. A comparison of normalization methods for high density oligonucleotide array data based on variance and bias. Bioinformatics. 2003;19:185-93.

10. Bisognin A, Sales G, Coppe A, Bortoluzzi S, Romualdi C. MAGIA (2): from miRNA and genes expression data integrative analysis to microRNAtranscription factor mixed regulatory circuits (2012 update). Nucleic Acids Res. 2012;40:W13-21.

11. Su G, Morris JH, Demchak B, Bader GD. Biological network exploration with Cytoscape 3. Curr Protoc Bioinform / editoral board, Andreas D Baxevanis [et al]. 2014; 47: 813 1-24.

12. Kwon AY, Kim Gl, Jeong JY, Song JY, Kwack KB, Lee C, et al. VAV3 overexpressed in Cancer stem cells is a poor prognostic Indicator in ovarian Cancer patients. Stem Cells Dev. 2015;24:1521-35.

13. Bapat SA. Human ovarian cancer stem cells. Reproduction. 2010;140:33-41.

14. Azuara V, Perry P, Sauer S, Spivakov M, Jorgensen HF, John RM, et al. Chromatin signatures of pluripotent cell lines. Nat Cell Biol. 2006;8:532-8

15. Krones-Herzig A, Mittal S, Yule K, Liang H, English C, Urcis R, et al. Early growth response 1 acts as a tumor suppressor in vivo and in vitro via regulation of p53. Cancer Res. 2005;65:5133-43.

16. Liu Y, Elf SE, Miyata Y, Sashida G, Liu Y, Huang G, et al. p53 regulates hematopoietic stem cell quiescence. Cell Stem Cell. 2009;4:37-48.
17. Wilson A, Murphy MJ, Oskarsson T, Kaloulis K, Bettess MD, Oser GM, et al. CMyc controls the balance between hematopoietic stem cell self-renewa and differentiation. Genes Dev. 2004;18:2747-63.

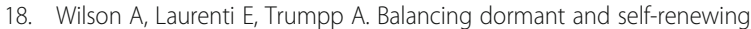
hematopoietic stem cells. Curr Opin Genet Dev. 2009;19:461-8.

19. Shachaf CM, Kopelman AM, Arvanitis C, Karlsson A, Beer S, Mandl S, et al. MYC inactivation uncovers pluripotent differentiation and tumour dormancy in hepatocellular cancer. Nature. 2004;431:1112-7.

20. Lopez-Ayllon BD, Moncho-Amor V, Abarrategi A, Ibanez de Caceres I, Castro-Carpeno J, Belda-Iniesta C, et al. Cancer stem cells and cisplatinresistant cells isolated from non-small-lung cancer cell lines constitute related cell populations. Cancer Med. 2014;3:1099-111.

21. Tao W, Shi JF, Zhang Q, Xue B, Sun YJ, Li CJ. Egr-1 enhances drug resistance of breast cancer by modulating MDR1 expression in a GGPPS-independent manner. Biomed Pharmacother = Biomed Pharmacother. 2013:67:197-202.

22. Khaitan D, Chandna S, Arya MB, Dwarakanath BS. Establishment and characterization of multicellular spheroids from a human glioma cell line. mplications for tumor therapy J Transl Med. 2006;4:12.

23. Zhang S, Balch C, Chan MW, Lai HC, Matei D, Schilder JM, et al. Identification and characterization of ovarian cancer-initiating cells from primary human tumors. Cancer Res. 2008;68:4311-20.

24. Ishiguro T, Sato A, Ohata H, Ikarashi Y, Takahashi RU, Ochiya T, et al. Establishment and characterization of an in vitro model of ovarian Cancer stem-like cells with an enhanced proliferative capacity. Cancer Res. 2016;76: 150-60.

25. Farahani E, Patra HK, Jangamreddy JR, Rashedi I, Kawalec M, Rao Pariti RK, et al. Cell adhesion molecules and their relation to (cancer) cell stemness. Carcinogenesis. 2014;35:747-59.

26. Efroni S, Duttagupta R, Cheng J, Dehghani H, Hoeppner DJ, Dash C, et al. Global transcription in pluripotent embryonic stem cells. Cell Stem Cell. 2008;2:437-47

27. Huang RP, Fan Y, deBelle I, Ni Z, Matheny W, Adamson ED. Egr-1 inhibits apoptosis during the UV response: correlation of cell survival with Egr-1 phosphorylation. Cell Death Differ. 1998:5:96-106.

28. Cancer Genome Atlas Research N. Integrated genomic analyses of ovarian carcinoma. Nature. 2011;474:609-15.

29. Cheng $T$, Rodrigues $N$, Shen $H$, Yang $Y$, Dombkowski D, Sykes $M$, et al. Hematopoietic stem cell quiescence maintained by p21cip1/waf1. Science 2000;287:1804-8.

30. Rahl PB, Lin CY, Seila AC, Flynn RA, McCuine S, Burge CB, et al. C-Myc regulates transcriptional pause release. Cell. 2010;141:432-45.

31. Johnson EL, Robinson DG, Coller HA. Widespread changes in mRNA stability contribute to quiescence-specific gene expression patterns in a fibroblast model of quiescence. BMC Genomics. 2017:18:123.

32. Hu B, Zhang H, Wang Z, Zhang F, Wei H, Li L. LncRNA CCAT1/miR-130a-3p axis increases cisplatin resistance in non-small-cell lung cancer cell line by targeting SOX4. Cancer Biol Ther. 2017;18:974-83.

33. Jung JG, Shih IM, Park JT, Gerry E, Kim TH, Ayhan A, et al. Ovarian Cancer Chemoresistance relies on the stem cell reprogramming factor PBX1. Cancer Res. 2016:76:6351-61.

34. Ficara F, Murphy MJ, Lin M, Cleary ML. Pbx1 regulates self-renewal of longterm hematopoietic stem cells by maintaining their quiescence. Cell Stem Cell. 2008:2:484-96.

35. Asaduzzaman M, Constantinou S, Min H, Gallon J, Lin ML, Singh P, et al. Tumour suppressor EP300, a modulator of paclitaxel resistance and stemness, is downregulated in metaplastic breast cancer. Breast Cancer Res Treat. 2017:163:461-74

36. Tirino V, Desiderio V, Paino F, De Rosa A, Papaccio F, La Noce M, et al. Cancer stem cells in solid tumors: an overview and new approaches for their isolation and characterization. FASEB J : Official Publication Fed Am Soc Exp Biol. 2013;27:13-24.

\section{Publisher's Note}

Springer Nature remains neutral with regard to jurisdictional claims in published maps and institutional affiliations. 